\title{
Investigation of Seakeeping Characteristics of High-Speed Catamarans in Waves
}

Chih-Chung Fang

Ph.D. United Ship Design and Development Centre, Taiwan, R.O.C., ccfang@mail.usddc.org.tw

Hoi-Sang Chan

Ph.D. School of Marine Science and Technology, University of Newcastle, UK.

Follow this and additional works at: https://jmstt.ntou.edu.tw/journal

Part of the Engineering Commons

\section{Recommended Citation}

Fang, Chih-Chung and Chan, Hoi-Sang (2004) "Investigation of Seakeeping Characteristics of High-Speed Catamarans in Waves," Journal of Marine Science and Technology. Vol. 12: Iss. 1, Article 2.

DOI: $10.51400 / 2709-6998.2215$

Available at: https://jmstt.ntou.edu.tw/journal/vol12/iss1/2

This Research Article is brought to you for free and open access by Journal of Marine Science and Technology. It has been accepted for inclusion in Journal of Marine Science and Technology by an authorized editor of Journal of Marine Science and Technology. 


\title{
INVESTIGATION OF SEAKEEPING CHARACTERISTICS OF HIGH-SPEED CATAMARANS IN WAVES
}

\author{
Chih-Chung Fang* and Hoi-Sang Chan**
}

Key words: seakeeping performance, wave-piercing catamaran, oblique waves, three-dimensional.

\begin{abstract}
This paper presents the motion characteristics for high-speed catamarans travelling in waves. Two mathematical models, threedimensional translating-pulsating source distribution technique and three-dimensional pulsating source distribution technique, are used for predicting the motions of the wave-piercing catamaran in oblique waves. The comparison between numerical predictions and experimental data carried out in SSPA shows a good agreement except the one around the resonance regions of pitch motion. It may be due to the nonlinear effects of centre bow with large pitch motions in waves. The phase angles show some scatters in the high frequencies region at stern waves. The dynamic motions of the wave-piercing catamaran have been investigated by means of short-term statistical analysis with three-dimensional pulsating source distribution technique. The comparison of seakeeping performance between the conventional catamaran and the wave-piercing catamaran has been discussed
\end{abstract}

\section{INTRODUCTION}

The use of fast marine vehicles for the transportation of passengers and cargoes has been increasing for the past several years. According to Jane's High-Speed Marine Transportation report (Phillips, 1999), the last few years have seen an average annual increase in demand of 15 percent that is equivalent to a doubling in the fast ferry fleet capacity every five years. Highspeed catamarans with a super slender twin-hull form are the most attractive option for a large high-speed passenger ferry because of its large deck and good transverse stability. However, It has been noticed that the high-speed craft shows a low seakeeping performance in moderate to rough sea conditions due to her relatively light-weight and high travelling speed. Furthermore, if the relative motion between the wave

Paper Submitted 10/23/03, Accepted 11/28/03. Author for Correspondence: Chih-Chung Fang. E-mail: ccfang@mail.usddc.org.tw.

*Ph.D. United Ship Design and Development Centre, Taiwan, R.O.C.

**Ph.D. School of Marine Science and Technology, University of Newcastle, $U K$. and ship becomes large, the semi-displacement catamaran is vulnerable to wave impacts on the bottom of the cross-deck in bow seas and bow dive in following seas. It may cause speed reductions, local structural damage and severe safety problem (Fang, 1996). A series of systematic theoretical and experimental investigations of motions and sea loads of catamarans was carried out at the Naval Ship Research and Development Centre. An extensive experimental programme with ASR (submarine rescue ship) catamaran model was conducted by Wahab et al. (1971) to investigate the behaviour of the ASR model in a seaway. The full and model scale experimental programme conducted with Hayes catamaran were presented by Hadler et al. (1974). Lee et al. (1973) studied the twin-hull motion problems by using the strip method which was the extension of the approach developed by Salvesen et al. (1970). Based upon Chapman's (1975) high speed theory which was proposed to formulate a vertical surface-piercing plate motions in unsteady yaw and sway, Faltinsen $e t$ al. (1992) and Ohkusu and Wen (1995) reported a kind of pseudo three-dimensional theory to evaluate the motion responses of a catamaran at high Froude number. The three-dimensional translating and oscillating source technique was applied by Chan (1993) and Hudson et al. (1995) to predict the seakeeping performance of multihull ships. Kring and Sclavounos (1991) reported a three-dimensional Rankine panel method to investigate the wave patterns and motions for multi-hull ships travelling with forward speed through head seas. Most of these investigations are limited to the linear motions of catamarans in small amplitude waves.

The concept of wave-piercing catamaran was conceived in 1983 with a test craft, Little Devil, in Australia. Furthermore, the first $74 \mathrm{~m}$ wave-piercing catamaran passenger car ferry Hoverspeed Great Britain was delivered by Incat Australia PTY LTD in 1990 (Phillips, 2000). The wave-piercing catamaran configuration consists of a centre bow hull and two slender side hulls (Figure 2). The centre bow hull is connected with two side hulls by means of a cross structure, which offer useful deck area. This complex hull form shows out- 
standing seakeeping capability in waves (Soars, 1992). But the relatively high structural weight ratio inherent to catamaran configurations must be overcome in order to offer a competitive price in the international fast ferry market.

This paper presents some of the theoretical results obtained by two mathematical models, three-dimensional translating pulsating source distribution technique (3DT) and three- dimensional pulsating source distribution technique (3DP), for predicting the seakeeping characteristics of high-speed catamarans at seas. Furthermore, the numerical results are compared with model experiments carried out at SSPA to investigate the dynamic motion response of a wave-piercing catamaran (CAT-I) advancing in oblique waves.

\section{THEORETICAL BACKGROUND}

Since the theoretical development of a three-dimensional potential technique for the calculations of ship motions and sea loads on an arbitrary three-dimensional body can be found elsewhere (Chan, 1990), the theoretical background will be only outline here.

When a ship advances at constant mean forward speed $U$ in regular sinusoidal waves with small amplitude, the ship's heading can be defined by angle $\beta$ $\left(180^{\circ}\right.$ at head seas). The wave frequency $\omega_{0}$ is related to the ship's frequency of encounter $\omega$ by

$$
\omega=\left|\omega_{0}-U k \cos \beta\right|
$$

with $k=\frac{\omega_{0}^{2}}{g}$, here $\mathrm{k}$ is the wave number.

Figure 1 shows the right-hand coordinate system o-xyz which moves in the same direction and speed as the moving body. The $x$-axis is pointing upstream parallel to the longitudinal plane of the body and the $z-$ axis is pointing vertically upward through the centre of gravity of the body with the origin in the plane of the mean free surface. The body is assumed rigid and oscillates in six degrees of freedom about its mean position with complex amplitudes $\xi_{j}(j=1,2, \ldots 6)$. Here

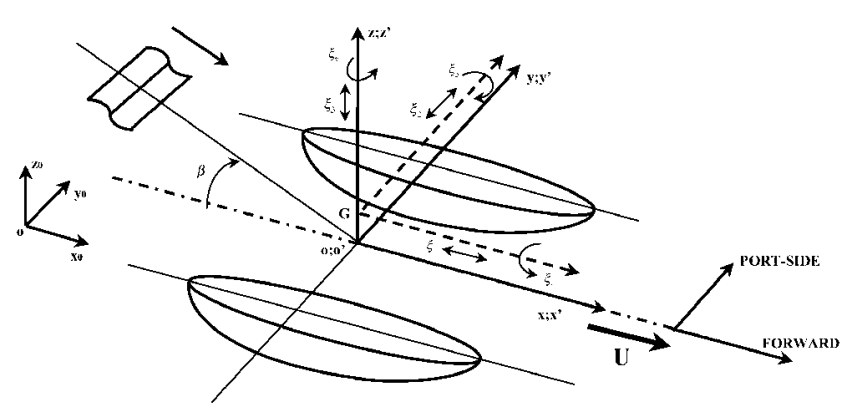

Fig. 1. Coordinate system of twin-hulls. $j=1,2,3,4,5,6$ refer to surge, sway, heave, roll, pitch, and yaw modes of motion respectively.

For dynamic equilibrium the total wave-induced forces must be equal to the mass inertia forces and the coupled linear equations of motion of the rigid body can be written as

$$
\sum_{k=1}^{6}\left\{\left(M_{j k}+A_{j k}\right) \xi_{k}+B_{j k} \xi_{k}+C_{j k} \xi_{k}\right\}=F_{j}^{W}+F_{j}^{V}
$$

where $\xi_{k}$ and $\xi_{k}$ are motion acceleration and velocity respectively; $M_{j k}$ is the mass matrix; $A_{j k}$ is the added mass; $B_{j k}$ is the damping; and $C_{j k}$ is the restoring coefficient. $F_{j}^{W}$ is the wave exciting force; $F_{j}^{V}$ is the excitation force due to viscous effects. The indices $j$ and $k$ indicate the direction of the fluid force and the mode of motion respectively. Details about the cross-flow approach for taking viscous effects into account can be found in Chan (1993).

Within the framework of potential theory, the fluid is assumed to be ideal and incompressible. By using the perturbation procedures, the total velocity potential $\Phi\left(\vec{x}_{0}, t\right)$ of the flow field due to the forward and oscillatory motions of the body under the action of waves can be expressed as

$$
\Phi\left(\vec{x}_{0}, t\right)=-U x+\bar{\Phi}(\vec{x})+\tilde{\Phi}(\vec{x}, t)
$$

where $\bar{\Phi}(\vec{x})$ is the steady perturbation potential due to forward motion and $\tilde{\Phi}(\vec{x}, t)$ denotes the unsteady velocity potential due to incident waves, diffraction and radiation waves, which can be written as

$$
\tilde{\Phi}(\vec{x}, t)=\left[\zeta_{0}\left(\phi_{0}+\phi_{7}\right)+\sum_{j=1}^{6} \bar{\xi}_{j} \phi_{j}\right] e^{-i \omega t}
$$

with

$$
\phi_{0}=-i \frac{g}{\omega_{0}} e^{k z+i k(x \cos \beta+y \sin \beta)}
$$

in which $\phi_{0}$ is the incident wave potential of amplitude, $\zeta_{0}, \phi_{7}$ is the diffraction wave potential and $\phi_{j}$ is the radiation wave potential in $j$-th mode of motion.

The unsteady motions of the ship and the fluid are assumed to be small so that the unsteady body boundary and free surface conditions can be linearised. With the basic linear assumption, the diffraction wave potential $\phi_{7}$ and the radiation wave potential $\phi_{j}$, in the $j$-th mode of motion, must satisfy the following linearised boundary conditions:

Laplace's equation in the fluid domain

$$
\nabla^{2} \phi_{j}=0 ; j=1,2, \ldots 7
$$

the linearised free-surface condition 


$$
(i \omega+U \partial / \partial x)^{2} \phi_{j}+g \frac{\partial \phi_{j}}{\partial z}=0 \quad j=1,2, \ldots 7 \text { at } z=0
$$

the kinematic body boundary condition

$$
\frac{\partial \phi_{j}}{\partial n}=-i \omega n_{j}+m_{j} \quad j=1,2, \ldots 6 \text { on } S_{B}
$$

and

$$
\frac{\partial \phi_{7}}{\partial n}=-\frac{\partial \phi_{0}}{\partial n} \quad \text { on } S_{B}
$$

the kinematic boundary condition on the ocean floor

$$
\frac{\partial \phi_{j}}{\partial n}=0 \quad j=1,2, \ldots 7 \text { at } z \rightarrow-\infty ;
$$

where $g$ is acceleration due to gravity; $n_{j}$ is the generalised direction cosine with $\vec{n}=\left(n_{1}, n_{2}, n_{3}\right)$ and $\vec{r}^{\prime} \times \vec{n}=\left(n_{4}, n_{5}, n_{6}\right) ; \vec{n}$ is a unit normal vector outward to the mean wetted body surface and $\vec{r}$ is a position vector of a point on the mean wetted body surface; $\left(m_{1}\right.$, $\left.m_{2}, m_{3}\right)=-(\vec{n} \cdot \nabla) \vec{W}$ and $\left(m_{4}, m_{5}, m_{6}\right)=$ $-(\vec{n} \cdot \nabla)\left(\vec{r}^{\prime} \times \vec{W}\right)$; and $\vec{W}$ is a steady velocity field. If the body is slender, the steady perturbation potential due to forward motion is negligible in the unsteady flow. Then $m_{j}=0$ for $j=1,2,3,4 ; m_{5}=U n_{3}$ and $m_{6}=$ $-U n_{2}$, which are used in the present study.

The solution of the linearised unsteady forward motion is constructed by means of the three-dimensional Green function for solving the boundary integral equation. The three-dimensional Green function integral equation is formed by the surface integral over the mean wetted body surface and the free-surface contour integral along the intersection curve between the mean wetted body surface and the undisturbed free surface in the form

$$
\begin{aligned}
4 \pi \phi_{j}(p) & =\iint_{S_{B}} \sigma(q) G(p ; q) d s(q) \\
& +\frac{U^{2}}{g} \oint_{L_{0}} n_{1} \sigma(q) G(p ; q) d l(q)
\end{aligned}
$$

where $G(p ; q)$ is a translating-pulsating source function at the field point $p$ due to a source of unknown strength $\sigma(q)$ at the source point $q$.

The unknown source strength $\sigma(q)$ can be determined using the appropriate body boundary condition (8) and (9). Thus

$$
\begin{aligned}
2 \pi \sigma(p) & +\iint_{S_{B}} \sigma(q) \frac{\partial G(p ; q)}{\partial n_{p}} d s(q) \\
& +\oint_{L_{0}} n_{1} \sigma(q) \frac{\partial G(p ; q)}{\partial n_{p}} d l(q)=4 \pi \frac{\partial \phi_{j}(p)}{\partial n_{p}}
\end{aligned}
$$$$
\text { for } p \text { on } S_{B}
$$

Chan (1990) showed that the translating- pulsating source function $G(p ; q)$ may be expressed in the form

$$
G(p ; q)=-\frac{1}{r}+\frac{1}{r}-N\left(p ; f ; F_{n}\right)-W\left(p ; f ; F_{n}\right)
$$

where $r$ is the distance between the field point $p$ and the source point $q . r$ is the distance between the field point $p$ and the image sink point $q$ '. $N\left(p ; f ; F_{n}\right)$ and $W\left(p ; f ; F_{n}\right)$ are the local disturbance function and the wave-like farfield function, which may be written as

$$
\begin{aligned}
N\left(p ; f ; F_{n}\right) & =\sum_{j=1}^{2}\left\{\frac{1}{\pi}\left[-i \int_{0}^{\gamma} \frac{Q_{j}}{\sqrt{4 \tau \cos \theta-1}} d \theta+\int_{\gamma}^{\pi} \frac{Q_{j}}{\sqrt{1-4 \tau \cos \theta}} d \theta\right]\right. \\
& \left.-2 \oint_{0}^{\gamma} \frac{H\left(-\operatorname{Im} Z_{1 j}\right) k_{1} \exp \left(Z_{1 j}\right)+H\left(\operatorname{Im} Z_{2 j}\right) k_{2} \exp \left(Z_{2 j}\right)}{\sqrt{4 \tau \cos \theta-1}} d \theta\right\}
\end{aligned}
$$

$$
\begin{aligned}
W\left(p ; f ; F_{n}\right) & =\sum_{j=1}^{2} i 2\left[\int_{\gamma}^{\frac{\pi}{2}} \frac{H\left(t_{j}\right) k_{1} \exp \left(Z_{1 j}\right)+H\left(-t_{j}\right) k_{2} \exp \left(Z_{2 j}\right)}{\sqrt{1-4 \tau \cos \theta}} d \theta\right. \\
& \left.+\int_{\frac{\pi}{2}}^{\pi} \frac{H\left(t_{j}\right)\left[k_{1} \exp \left(Z_{1 j}\right)-k_{2} \exp \left(Z_{2 j}\right)\right.}{\sqrt{1-4 \tau \cos \theta}}\right]
\end{aligned}
$$

with

$$
\begin{aligned}
Q_{j} & =k_{1} \exp \left(Z_{1 j}\right) E_{1}\left(Z_{1 j}\right)-\frac{k_{1}}{Z_{1 j}}-k_{2} \exp \left(Z_{2 j}\right) E_{1}\left(Z_{2 j}\right) \\
& +\frac{k_{2}}{Z_{2 j}} \text { for } j=1,2
\end{aligned}
$$

where $f$ is non-dimensional frequency $(f=\omega \sqrt{L / g})$ and $F_{n}$ is the Froude number $\left(F_{n}=U / \sqrt{g L}\right)$.

In this study, a high-frequency assumption may be made that the frequency of oscillation $\omega$ is much higher than the differential operator $U \partial / \partial x$ in the free surface boundary condition (7) which leads to the use of a simplified three-dimensional pulsating source distribution technique (3DP). For oscillating source model, the Green function $G(p ; q)$ is a zero speed limit of the translating-pulsating source function and the water-line contours in the integral eqns (11) to (12) disappear.

Hydrodynamic coefficients, $A_{j k}, B_{j k}$, and wave exciting forces, $F_{j}^{W}$, given in equation (2) can be obtained after solving the three-dimensional Green function integral equation which satisfies the slender body boundary condition.

\section{COMPARISONS BETWEEN PREDICTIONS AND MEASUREMENTS}

Model tests were carried out in SSPA's Maritime Dynamic Laboratory with a free-running model. The 
laboratory has a basin with the dimension $88 \mathrm{~m} \times 39 \mathrm{~m}$ with a variable water depth up to $3.0 \mathrm{~m}$. A multi-motion carriage spans the whole basin. The maximum speed of the carriage is $3.5 \mathrm{~m} / \mathrm{s}$.

Wave generators are located along one long and one short side with wave absorbers at the opposite sides. The wave generators can produce long-crested regular and irregular waves and about $0.4 \mathrm{~m}$ for regular waves depend on the wave period.

During the model tests, the response amplitude operators (RAO) of the wave-piercing catamaran for surge, sway, heave, pitch, roll and yaw motion as well as the phase angles related to the wave elevation at the C.G. section were measured at a nominal speed of 20 knots in the regular and irregular waves for a wide range of wave headings.

Numerical computations have been carried out to predict the dynamic motion responses of the CAT-I catamaran in oblique waves by using two types of singularity (3DT and 3DP). Configuration of the CATI catamaran is shown in Figure 2. Some of the main particulars are given in Table 1.

\section{Motion Responses in Oblique Waves}

Figures 3 to 7 show some of the selected motion

Table 1. Principal particulars of the CAT-I

\begin{tabular}{lc}
\hline & CAT-I \\
\hline LBP, L $(\mathrm{m})$ & 40.50 \\
Beam overall, B(m) & 12.50 \\
Beam of each hull at LWL $(\mathrm{m})$ & 3.40 \\
Draught, D(m) & 1.50 \\
Hull spacing between hull centre-line $(\mathrm{m})$ & 9.10 \\
Displacement(tonnes) & 223.0 \\
VCG $(\mathrm{m})$ & 4.05 \\
LCG aft of F.P. $(\mathrm{m})$ & 24.01 \\
Radius of gyration $K_{x x}(\mathrm{~m})$ & 4.37 \\
Radius of gyration $K_{y y}(\mathrm{~m})$ & 11.32 \\
Radius of gyration $K_{z z}(\mathrm{~m})$ & 11.89 \\
\hline
\end{tabular}

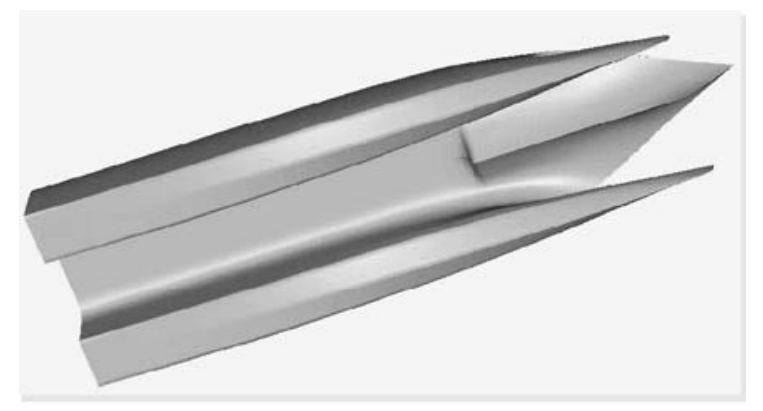

Fig. 2. Configuration of the wave-piercing catamaran (CAT-I).
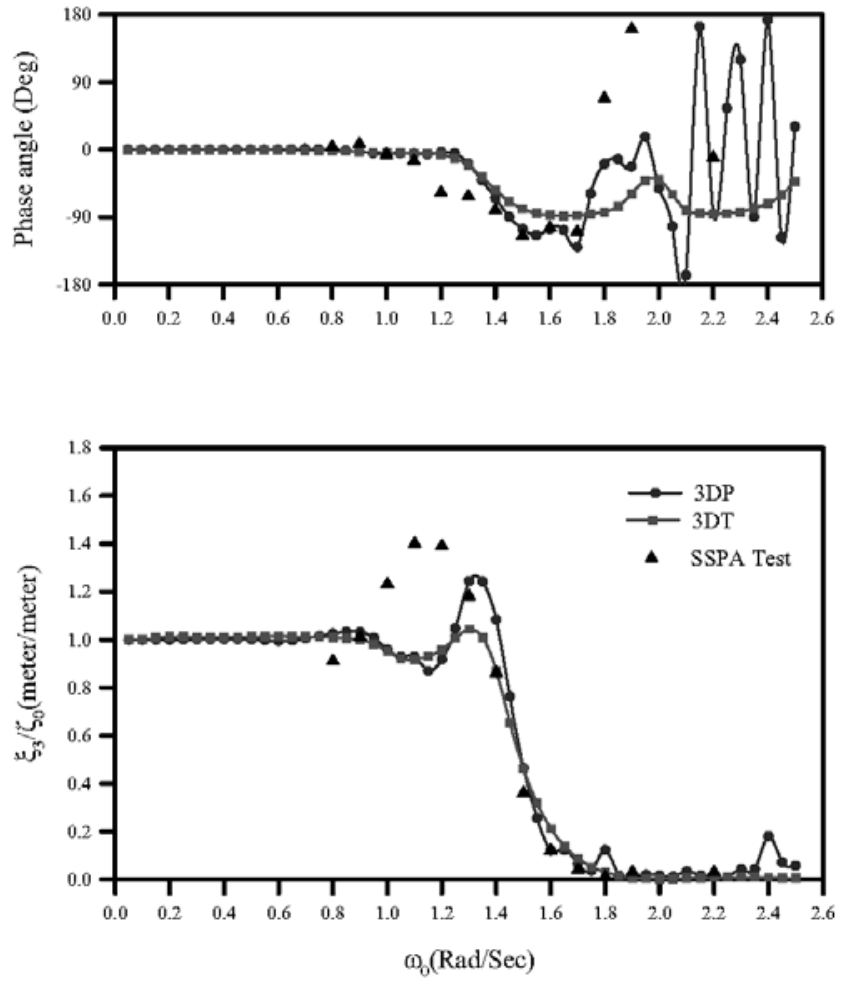

Fig. 3. Heave motion response of the CAT-I at $V=20 \operatorname{knots}\left(\beta=120^{\circ}\right)$.
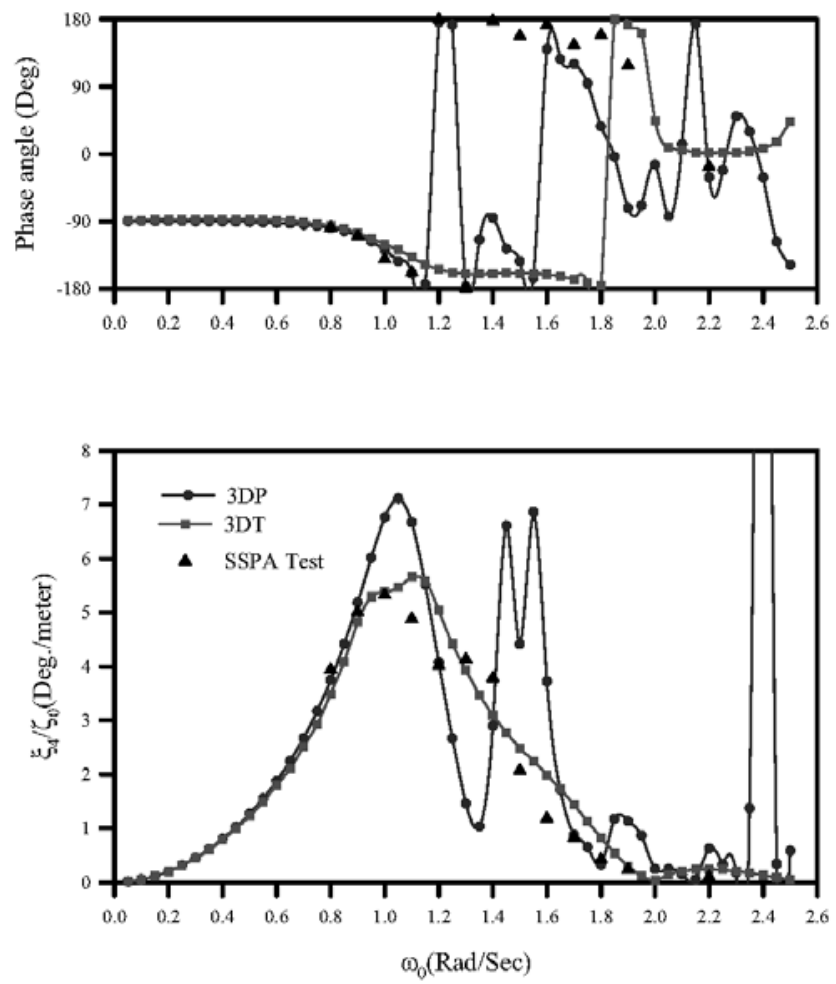

Fig. 4. Roll motion response of the CAT-I at $V=20$ knots $\left(\beta=120^{\circ}\right)$. 
responses and phase angles of the CAT-I at a nominal speed of 20 knots $(F n=0.52)$ in oblique waves. A positive phase angle of the motion response indicates that a motion reaches its positive maximum value before the crest of the undisturbed incoming regular wave passes the origin. It is observed that the difference between the theoretical results obtained by these two modellings is insignificant for the vertical motion response as shown in Figures 3 and 5. There is a good correlation between theoretical and experimental results except the one around the resonance region of pitch motions (Figure 5). The experimental measurements are lower than numerical predictions. It may be caused by the nonlinear effects of centre bow during large amplitude motions. These nonlinear behaviours can not be forecasted by using the linearised approaches as presented in this paper. However, the correlation between numerical predictions obtained from the 3DT and experimental data carried out in SSPA shows good agreement for the dynamic roll motion responses (Figure 4). It is found that the $3 \mathrm{DT}$ technique gives better prediction than the 3DP model in bow waves since the 3DP method shows some error fluctuations at $\mathrm{rad} / \mathrm{sec}$ as shown in Figures 4 . In the stern waves $\left(\beta=75^{\circ}\right)$, the ship encounters the wave crests with longer periods. The correlation between the calculated and measured values of motion responses is excellent as shown in
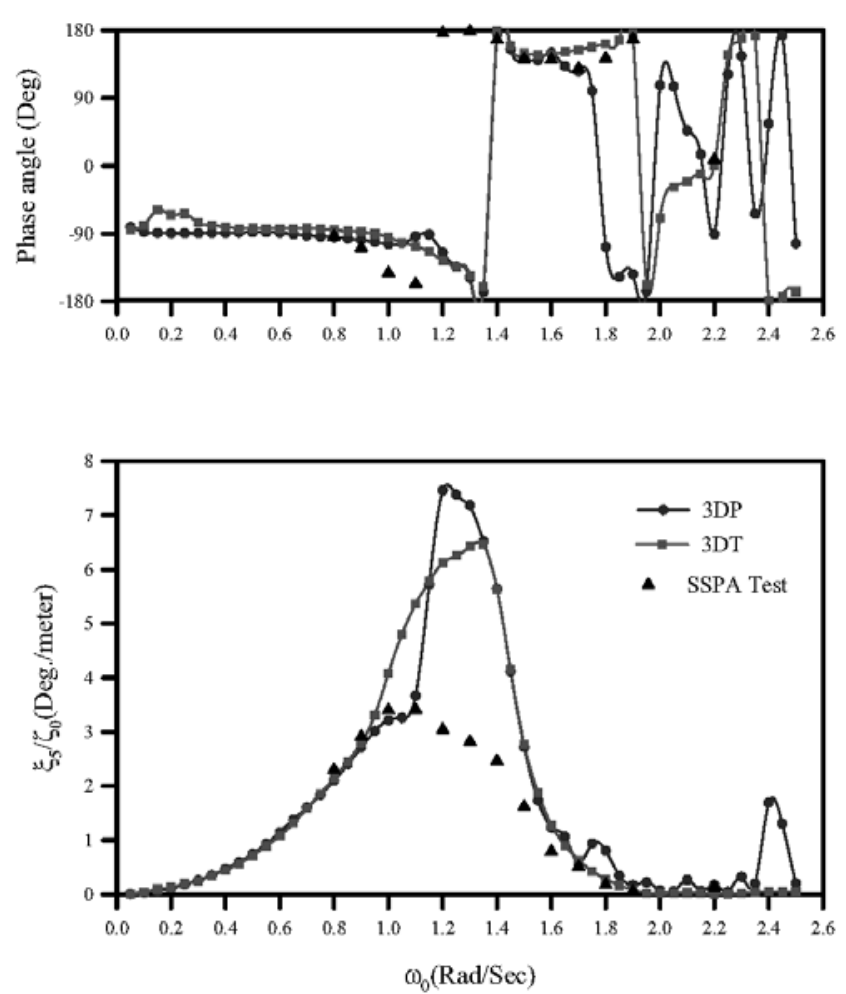

Fig. 5. Pitch motion response of the CAT-I at $V=20$ knots $\left(\beta=120^{\circ}\right)$.
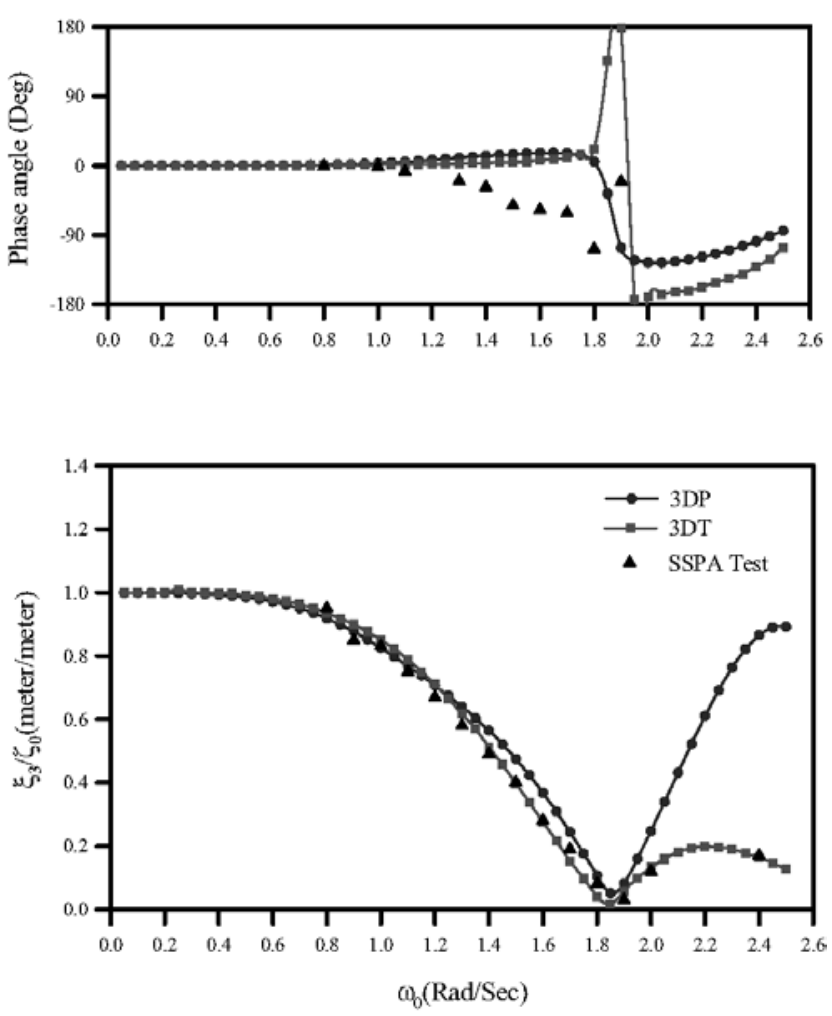

Fig. 6. Heave motion response of the CAT-I at $V=20$ knots $\left(\beta=75^{\circ}\right)$.
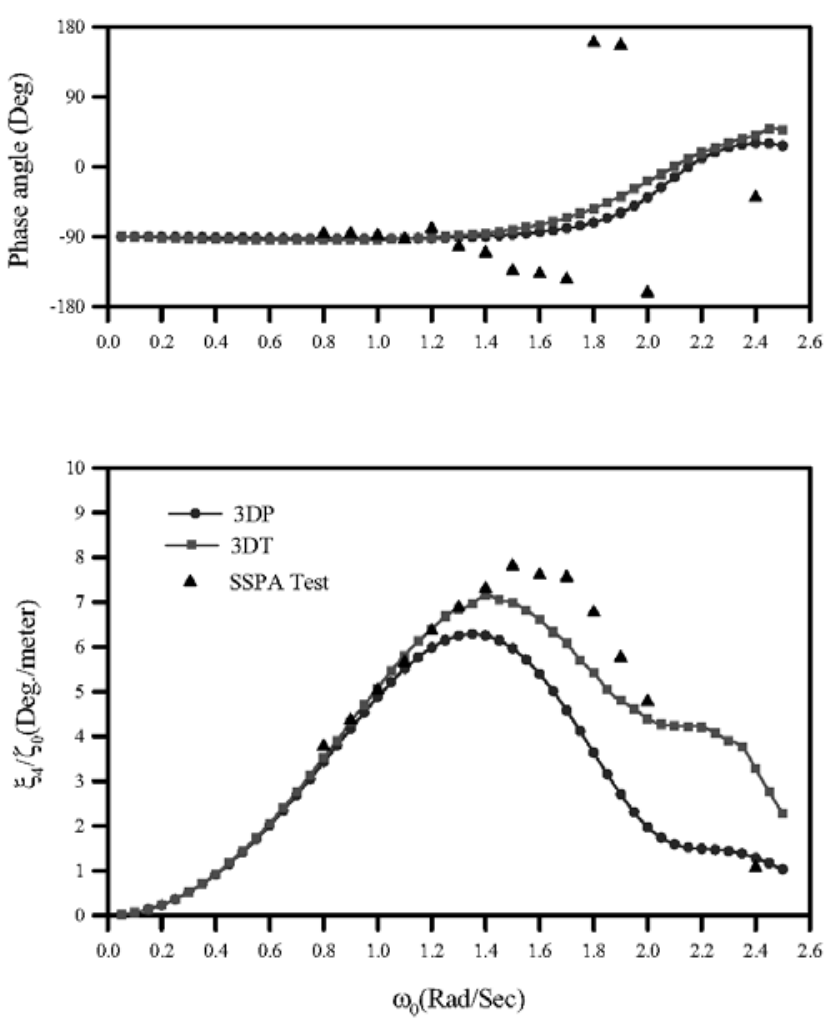

Fig. 7. Roll motion response of the CAT-I at $V=20$ knots $\left(\beta=75^{\circ}\right)$. 
Figures 6 and 7. It can be recognized that the 3DT method can provide more reliable predictions of motion responses than the simplified 3DP technique. The phase angles show some scatters in the high frequencies region. For the autopilot system, experimental errors may have occurred because it was not possible to keep the heading constant during the stern wave tests.

\section{Motion Responses in Irregular Waves}

The problem of ship motion in regular waves has been reduced to a manageable proportion through linearisation so that a practical solution can be obtained. The responses of a ship in irregular waves can be considered as the summation of the responses to regular waves of all frequencies. Thus, stochastic analysis can be carried out to predict the various statistical characteristics of motion and structural responses of the ship to irregular waves.

If the wave spectral density function of longcrested seas is denoted by $S(\omega)$, the area of response spectrum is given by

$$
m_{0}=\int_{0}^{\infty} R^{2}(\omega, U, \beta) S(\omega) d \omega
$$

where $R(\omega, U, \beta)$ is a response amplitude operator per unit amplitude of incident wave.

In this study, an ISSC wave spectrum has been used for the short-term statistical analysis for the catamaran travelling in seas. All statistical results are represented by the response root mean square (RMS) values. Figure 8 shows the roll motion response of the CAT-I at 20 knots in sea state $5\left(H_{1 / 3}=3.05, T_{0}=9 \mathrm{sec}\right)$. The roll motion responses predicted by the $3 \mathrm{DT}$ are lower than which obtained from the 3DP in bow sea condition but higher in stern sea condition. Same effects can be observed from the regular wave calculations (Figures 4 and 7). The comparison between numerical calculations and experiments shows a very good correlation.

Although the 3DT technique can account divergent and transverse wave system as well as interaction between the hulls at the high-speed range for the motion of catamaran, it is a more elaborate, numerically difficult and time-consuming method than the simplified 3DP model. In this study, using the three-dimensional pulsating source model, numerical computations have been performed for motion response predictions of the CAT-I which cover wave angles from $0^{\circ}$ to $180^{\circ}$ at $15^{\circ}$ intervals for seven different forward speeds from 0 to 30 knots. Speed Polar Plot has been developed to display the seakeeping boundaries between ship speeds and ship-wave heading angles associated with design criteria in a particular sea state.

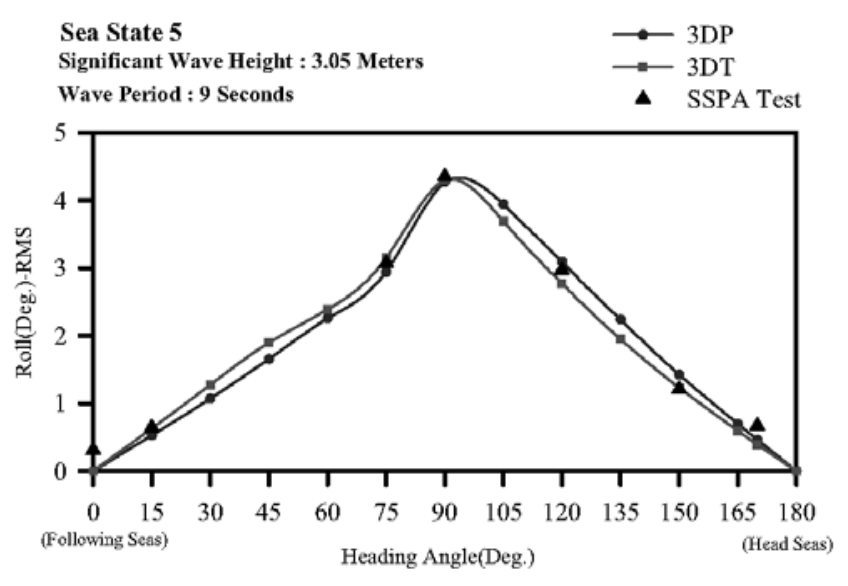

Fig. 8. Roll Motion Response of the CAT-I at $V=20$ knots (Sea State 5).

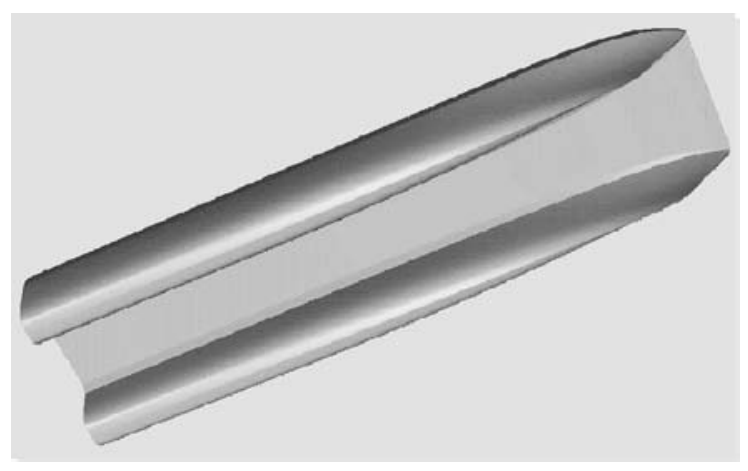

Fig. 9. Configuration of the conventional catamaran (CAT96).

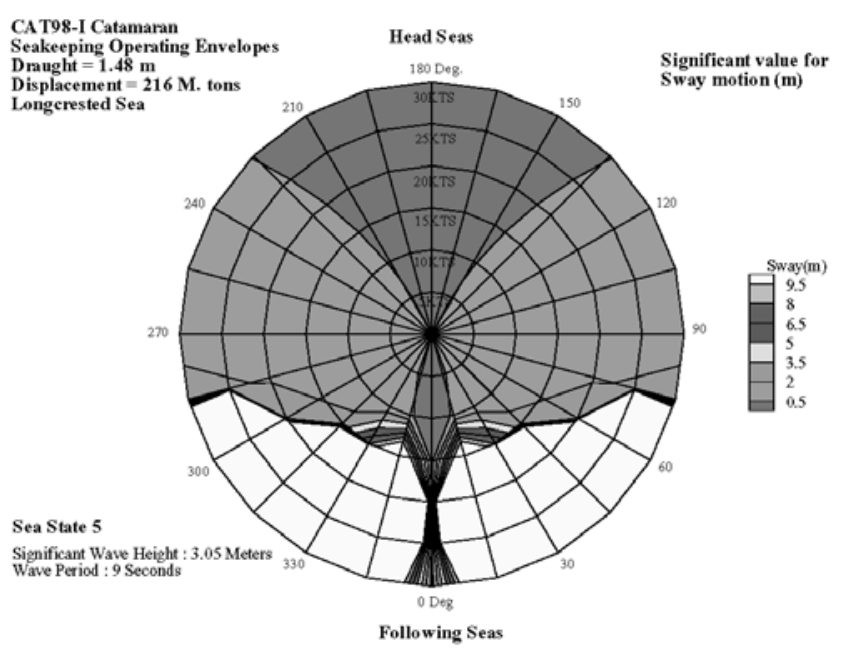

Fig. 10. Seakeeping operating envelopes for the CAT-I (Sway).

Figures 10 to 14 show the Speed Polar Plots for the CAT-I catamaran in sea state $5\left(H_{1 / 3}=3.05, T_{0}=9 \mathrm{sec}\right)$. Both heave and pitch motion responses are significant in long-crested bow seas but vanishingly small in long- 


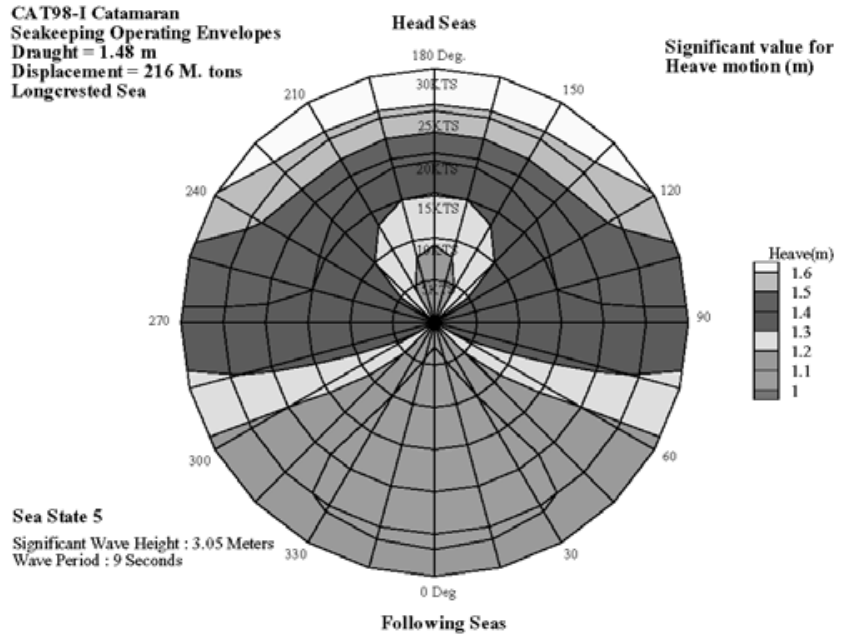

Fig. 11. Seakeeping operating envelopes for the CAT-I (Heave).

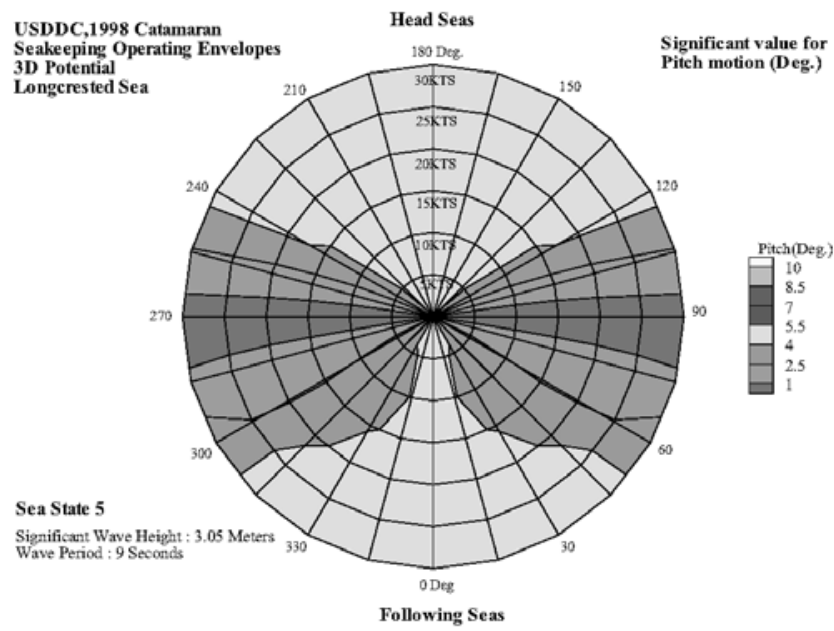

Fig. 12. Seakeeping operating envelopes for the CAT-I (Pitch).

crested beam seas. When the catamaran is travelling with forward speed, the amplitudes of vertical motion response increase. The maximum roll motion of the catamaran occurs in beam seas as shown in Figure 13. Based on the numerical and experimental investigation, the sway and yaw motion responses of the CAT-I are significant in stern waves (Figures 10 and 14). The plough-in in the following seas at high speed is the most severe safety problem for semi-displacement multihulls. However, the experimental and numerical investigations do show an excellent seakeeping characteristic of the wave-piercing catamaran (CAT-I) than conventional catamaran (CAT96, Figure 9) in oblique waves. The conventional catamaran may have some tendencies to bow dive in the following waves as reported by Fang

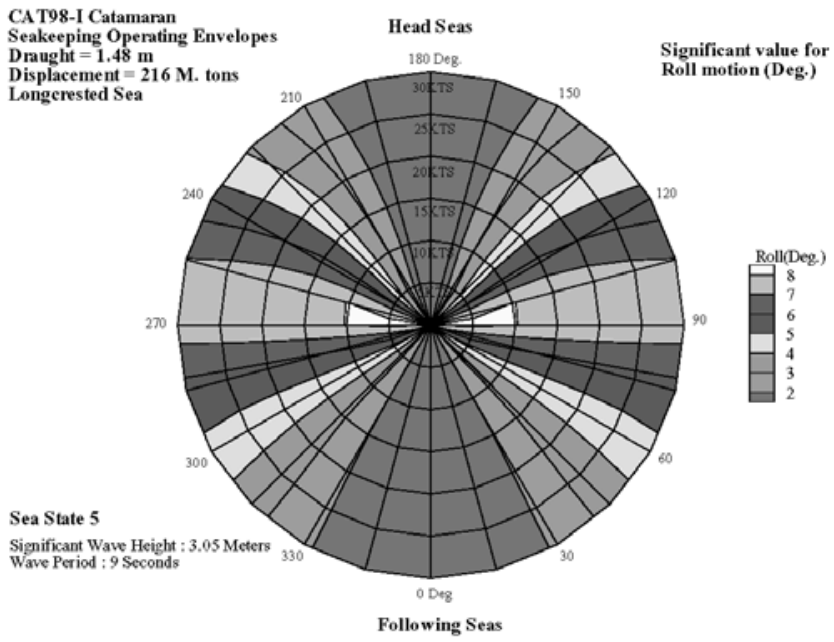

Fig. 13. Seakeeping operating envelopes for the CAT-I (Roll).

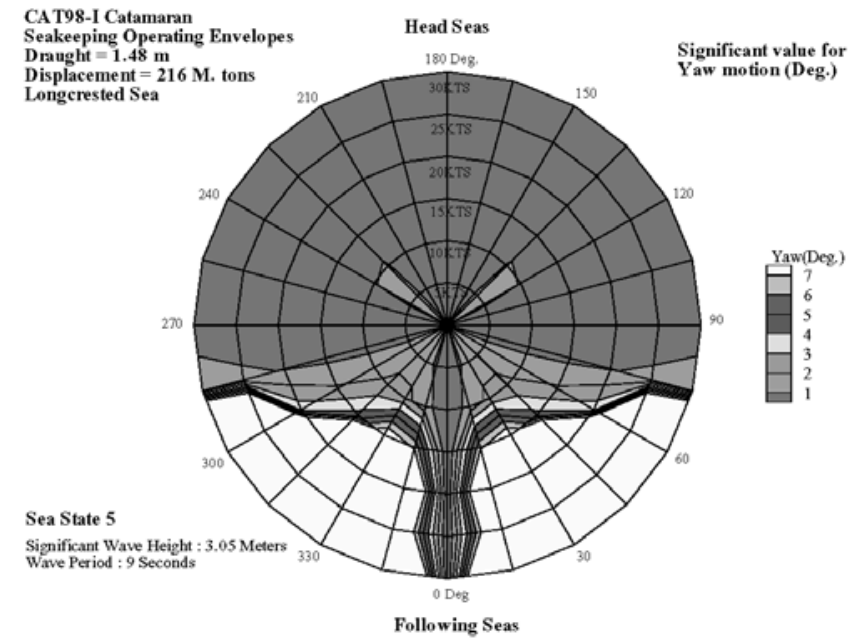

Fig. 14. Seakeeping operating envelopes for the CAT-I (Yaw).

et al. (1997) as shown in Figure 15.

\section{CONCLUSION}

Using two different three-dimensional source distribution techniques, numerical computations have been carried out for the wave-piercing catamaran advancing in regular waves. Although the linearised approach cannot forecast the nonlinear effects of the wave-piercing catamaran during the large amplitude motions, these approaches had been validated by the experimental data in this study and they provided some valuable information. The degree of confidence concerning real dynamic motion responses of high-speed catamarans was increased substantially for naval 


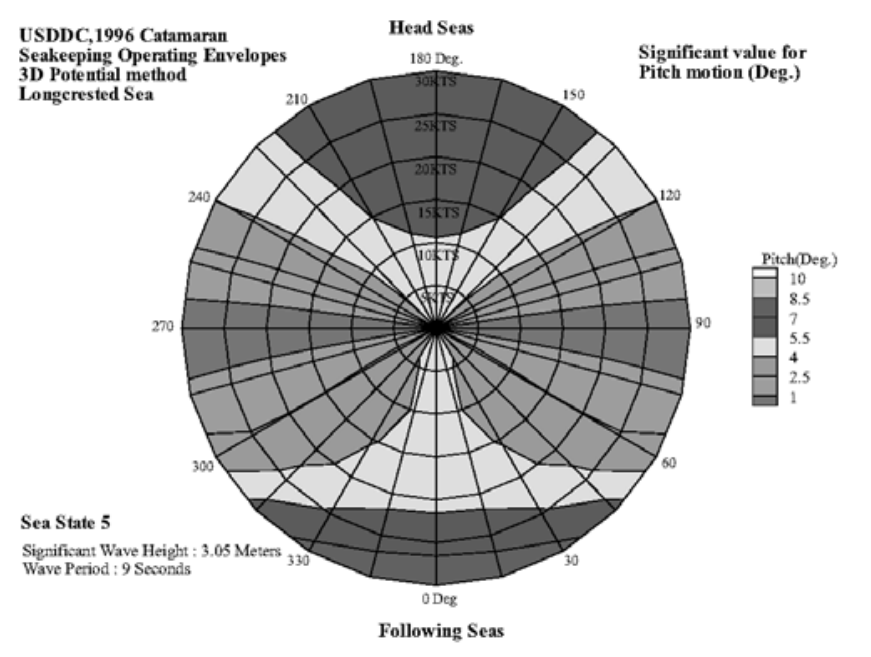

Fig. 15. Seakeeping operating envelopes for the CAT96 (Pitch).

architects.

Comparison of theoretical results of ship motions for the wave-piercing catamaran has been discussed. It is found that the difference between those results of ship motions obtained by these two modellings is insignificant. The comparison between numerical predictions and experimental data carried out in SSPA shows a good agreement except the one around the resonance region of pitch motions. The discrepancy may come from the nonlinear effects of centre bow during large pitch motions. The dynamic motions of the wave-piercing catamaran in irregular waves have been investigated by means of short-term statistical analysis with three-dimensional pulsating source distribution technique. The experimental data do show an excellent seakeeping characteristic of the wave-piercing catamaran (CAT-I) than conventional catamaran (CAT96) at seas. The conventional catamaran may have some tendencies to bow dive in the following waves.

\section{NOMENCLATURE}

$A_{j k} \quad$ hydrodynamic added mass.

$B_{j k} \quad$ hydrodynamic damping coefficient.

$C_{j k} \quad$ hydrostatic restoring coefficient.

$F_{j}^{w} \quad$ wave exciting force in $j$-th direction.

$F_{j}^{v} \quad$ exciting force due to viscous effects.

$F_{n} \quad$ Froude number $F_{n}=U / \sqrt{g L}$.

$G(p ; q)$ Green function.

$M_{i j} \quad$ element of mass matrix.

$S_{B} \quad$ mean wetted body surface.

$U$ mean forward speed of the body.

$g \quad$ gravitational constant.

$k \quad$ wave number.

$\vec{n} \quad$ normal vector outward the boundary surface. $\beta \quad$ angle of incident wave with $x$-axis.

$\Phi \quad$ total velocity potential of the flow field.

$\widetilde{\Phi} \quad$ velocity potential of unsteady flow.

$\phi_{0} \quad$ incident wave potential per unit amplitude.

$\phi_{j} \quad$ radiation wave potential per unit amplitude.

$\phi_{7} \quad$ diffraction wave potential per unit amplitude.

$\sigma \quad$ source strength.

$\omega \quad$ wave encounter frequency.

$\omega_{0} \quad$ Incident wave frequency.

$\zeta_{k} \quad$ motion response in $k$-th mode of motion.

$\nabla^{2} \quad$ Laplace's operator.

\section{REFERENCES}

1. Chan, H.S., "A Three-dimensional Technique for Predicting First and Second Order Hydrodynamic Forces on a Marine Vehicle Advancing in Waves," Ph. D. Dissertation, Department of Naval Architecture and Ocean Engine-ering, University of Glasgow (1990).

2. Chan, H.S., "Prediction of Motion and Wave Loads of Twin-Hull Ships," Marine Struct., 6, pp. 75-102 (1993).

3. Chapman, R.B.,"Numerical Solution for Hydrodynamic Forces on a Surface - Piercing Plate Oscillating in Yaw and Sway," Proc. of the 1st International Conference on Numerical Ship Hydrodynamics, DTNSRDC, Maryland, pp. 333-350 (1975).

4. Faltinsen, O., Hoff, J.R., Kvalsvold, J., and Zhao, R., "Global Loads on High-speed Catamarans," Proc. of the 5th International Symp. on Practical Design of Ships and Mobile Units, University of Newcastle-upon-Tyne, U. K., pp. 1360-1373 (1992).

5. Fang, C.C., "An Investigation of Motions of Catamarans in Regular Waves," Ph.D. Dissertation, Department of Naval Architecture and Ocean Engineering, University of Glasgow, March (1996).

6. Fang, C.C., Chan H.S., and Lu, C.Y., "Prediction of Motions and Wave Loads of a High Speed Catamaran at Seas," Proc. Eleventh Asian Technical Exchange and Advisory Meeting on Marine Structures, TEAM'97 Singapore, 16-18 December, pp. 385-392 (1997).

7. Hadler, J., B., Lee, C.M., Birmingham, J.T., and Jones, H.D., "Ocean Catamaran Seakeeping Design, Based on the Experiences of USNS Hayes," Transact. SNAME, Vol. 82, pp. 126-161 (1974).

8. Hudson, D.A., Price, W.G., and Temarel, P., "Seakeeping Performance of High Speed Displacement Craft," Proc. of the 3rd International Conference on Fast Sea Transportation, Lubeck-Travemunde, Germany, September, pp. 877-892 (1995).

9. Kring, D. and Sclavounos, P.D., "A New Method for Analyzing the Seakeeping of Multi-Hull Ships," Proc. the 1st International Conference on Fast Sea Transportation, Norway, pp. 429-444 (1991).

10. Lee, C.M., Jones, H.D., and Curphey, R.M., "Prediction 
of Motion and Hydrodynamic Loads of Catamarans," Marine Technol., Vol. 10, No. 4, pp. 392-405 (1973).

11. Ohkusu, M. and Wen, G., "Seakeeping of a High Speed Catamaran in Oblique Seas," Trans. West-Japan Soc. Naval Archit., No. 89, pp. 55-66 (1995).

12. Phillips, S.J., "Jane's High-Speed Marine Transportation 1998/99," Jane's Information Group Limited, U.K. (1998).

13. Phillips, S.J., "Jane's High-Speed Marine Transportation 2000/01," Jane's Information Group Limited, U.K.
(2000).

14. Salvesen, N., Tuck, E.O., and Faltinsen, O., "Ship Motions and Sea Loads," Transact. SNAME, Vol. 78, pp. 250-287 (1970).

15. Soars, A.J., "The Hydrodynamic Development of Large Wave-piercing Catamarans," Advanced Multihull Designs Pty Ltd. (1992).

16. Wahab, R., Pritchett, C., and Ruth, L.C., "On the Behaviour of the ASR Catamaran in Waves," Marine Technol., 8, pp. 334-360 (1971). 